\title{
High Blood Pressure: What You Need to Know ${ }^{1}$
}

Linda B. Bobroff ${ }^{2}$

\section{It's important to know about high blood pressure}

High blood pressure, also called hypertension, increases your health risks. Your chance of getting heart disease or kidney disease, or of having a stroke is higher if you have high blood pressure.

Why worry? Heart disease is the number one killer of men and women in the U.S. Stroke is the third most common cause of death in this country.

About one in every three American adults has high blood pressure. It is especially dangerous because it often has no symptoms. And if you don't know that you have high blood pressure, you will not get medical help to lower it.

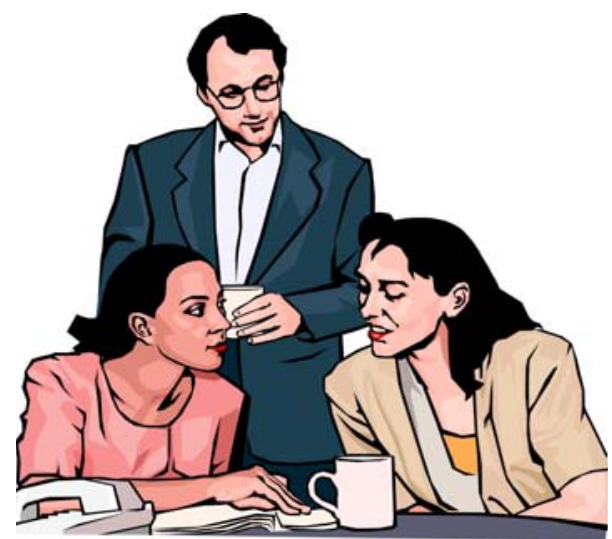

The good news is that you can find out if you have high blood pressure by having your blood pressure checked. If it is high, you can take steps to lower it. Just as important, if your blood pressure is normal, you can

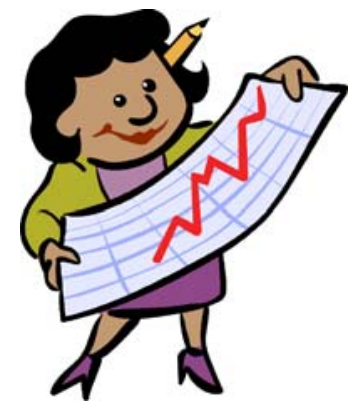
learn how to keep it from getting high. This fact sheet will help you make choices to stay healthy.

\section{What is blood pressure?}

Blood is carried from the heart to your body's organs in arteries. Each time your heart beats (about 60-70 times a minute at rest), it pumps blood into the arteries. Blood pressure is the force of the blood pushing against the walls of those arteries.

Blood pressure is highest when the heart contracts and pumps the blood. This is the systolic pressure. When your heart is at rest, between beats, the blood pressure falls. This is the diastolic pressure. It is normal for your blood pressure to

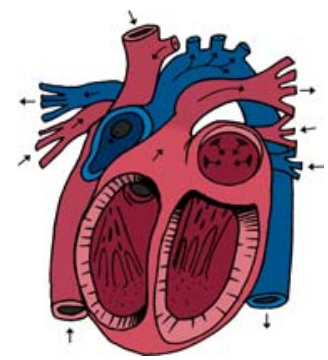
vary depending on what you are doing. For example, if you run for a bus, your blood pressure goes up. When you sleep at night, your blood pressure goes down.

1. This document is FCS8638, one of a series of the Department of Family, Youth and Community Sciences, Florida Cooperative Extension Service, Institute of Food and Agricultural Sciences, University of Florida. First published: March 2001. Revised August 2008. Please visit the EDIS Web site at http://edis.ifas.ufl.edu.

2. Adapted from the NHLBI/NIH fact sheet "Facts About How to Prevent High Blood Pressure” by Linda B. Bobroff, Ph.D., RD, LD/N, professor, Foods and Nutrition, Department of Family, Youth and Community Sciences, Institute of Food and Agricultural Sciences, University of Florida, Gainesville FL 32611. 


\section{What happens when blood pressure is high?}

Some people have blood pressure that stays high all or most of the time. Their blood pushes against the walls of their arteries with higherthan-normal force. If left untreated, this can lead to serious medical problems such as:

\section{Arteriosclerosis (hardening of the arteries)}



High blood pressure makes arteries thick and stiff. This speeds the build-up of cholesterol and fats in the arteries, and it prevents blood from flowing easily. In time, this can lead to a heart attack or stroke.

\section{Heart Attack}

Blood carries oxygen to all parts of the body. When the arteries that bring blood to the heart become blocked, the heart cannot get enough oxygen. This can cause chest pain (angina). In time, blood flow to the heart may be stopped completely, causing a heart attack.

\section{Kidney Damage}

The kidney acts as a filter to rid the body of wastes. High blood pressure causes blood vessels in the kidney to narrow and thicken. The kidney then filters less fluid and wastes build up in the blood. If the kidneys fail altogether, dialysis or a kidney transplant may be needed.

\section{$\underline{\text { Stroke }}$}

High blood pressure can cause arteries to narrow. If a blood clot blocks a narrowed artery



that goes to the brain, a stroke may occur. A stroke can also occur when high blood pressure causes a break in a weak blood vessel in the brain.

\section{Who's likely to develop high blood pressure?}

Anyone can develop high blood pressure, but some people are more likely to have it than

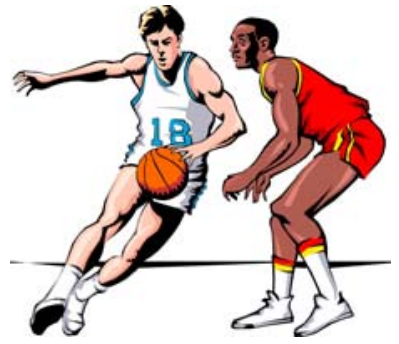
others. For example, high blood pressure is more common in African Americans than in whites.

In the early, middle adult years, men have

high blood pressure more often than women. But as men and women age, the reverse is true. More women after menopause have high blood pressure than men of the same age.

The number of both men and women with high blood pressure increases

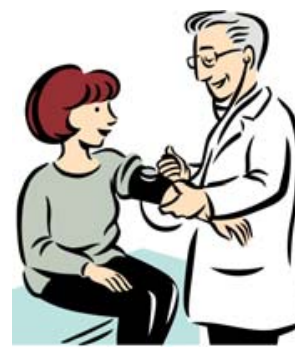
rapidly as we age. More than half of Americans over age 65 have high blood pressure.

Finally, heredity can affect your risk. If your parents or grandparents had high blood pressure, your risk is higher than if you have no family history.

While it is mainly a disease of adults, high blood pressure can occur in children. Even if everyone is healthy, be sure you and all of your family members get blood pressure levels checked on a regular basis.

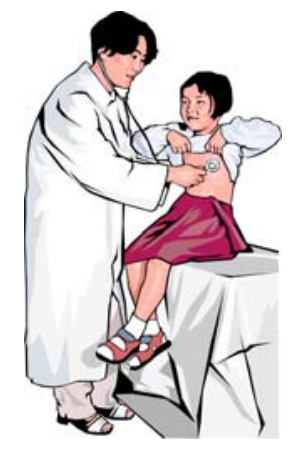




\section{How is blood pressure checked?}

Having your blood pressure checked is quick, easy, and painless. Blood pressure is measured with an instrument called a sphygmomanometer [sfig-moh-muh-nom-i-ter]. It works like this: A blood pressure cuff is wrapped around your upper arm and inflated. This stops blood flow in

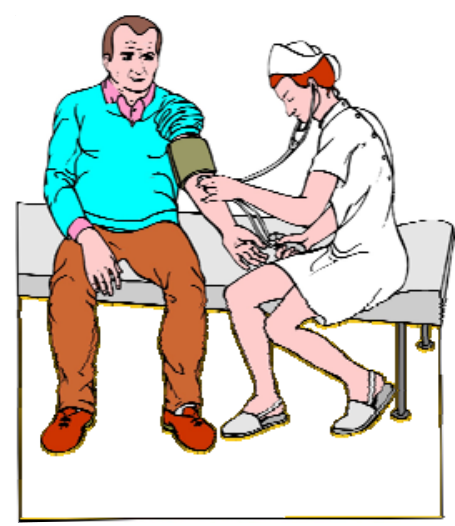
your artery for a few seconds. A valve is opened and air is released from the cuff; the sounds of your blood rushing through an artery are heard through a stethoscope.

The first sound heard is the systolic blood pressure. It represents the maximum pressure in the artery produced as the heart contracts and blood begins to flow. The last sound heard is the diastolic blood pressure. It represents the lowest pressure in the artery, when the heart is at rest.

\section{What do the numbers mean?}

Blood pressure is expressed with two numbers. They represent the systolic and diastolic pressures. These numbers are measurements of millimeters (mm) of mercury (Hg). Blood pressure is written with systolic number on the top and the diastolic number on the bottom. A blood pressure measurement of 120/80 mm Hg is expressed as "120 over $80 . "$

$120 \mathrm{mmHg}=$ Systolic $=$ Heart beating $80 \mathrm{mmHg}$ Diastolic Heart at rest
If your blood pressure is less than $120 / 80 \mathrm{~mm}$ $\mathrm{Hg}$, it is considered normal. If your systolic blood pressure is 120-139 OR your diastolic is 80-89 mm Hg, you have prehypertension. This means that you are at risk for high blood pressure and you should takes steps to lower it.

High blood pressure is more serious as the numbers get higher. The following table shows categories of blood pressure levels in adults.

\begin{tabular}{|c|c|c|c|}
\hline \multicolumn{4}{|c|}{ Classification of Blood Pressure (JNC7) } \\
\hline Category & SBP mmHg & & $\begin{array}{c}\text { DBP } \\
\mathrm{mmHg}\end{array}$ \\
\hline Normal & $<120$ & and & $<80$ \\
\hline Prehypertension & $120-139$ & or & $80-89$ \\
\hline Hypertension, Stage 1 & $140-159$ & or & $90-99$ \\
\hline Hypertension, Stage 2 & $\geq 160$ & or & $\geq 100$ \\
\hline \multicolumn{4}{|c|}{$\begin{array}{l}<\text { means "less than" } \\
\geq \text { means "greater than or equal to" }\end{array}$} \\
\hline \multicolumn{4}{|c|}{ Source: NIH Publication No. 03-5231; http://www.nhlbi.nih.gov } \\
\hline
\end{tabular}

\section{What causes high blood pressure?}

For most people, there is no known cause of high blood pressure. This is called "primary" or "essential" hypertension. Essential hypertension can't be cured, but it usually can be controlled. That's why it is important for everyone to have their blood pressure checked regularly.

In a few people, high blood pressure can be traced to a known cause, such as chronic kidney disease, use of birth control pills, or pregnancy. This type is called "secondary hypertension." It

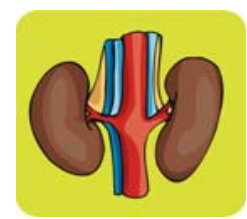
is usually cured if its cause is corrected or ends. 


\section{How can you prevent high blood pressure?}

Everyone - regardless of race, age, sex or heredity - can help lower their chance of developing high blood pressure. Here's how:

$\checkmark$ Aim for a healthy weight.

$\checkmark$ Be physically active each day.

$\checkmark$ Choose and prepare foods with less salt.

$\checkmark \quad$ Aim to eat at least 2 cups of fruit and $2 \frac{1}{2}$ cups of vegetables every day.

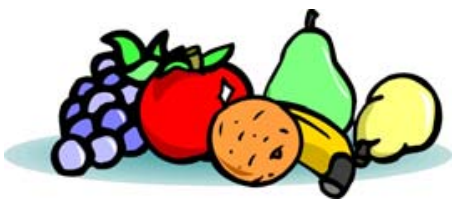

$\checkmark$ If you drink alcoholic beverages, do so in moderation.

If your blood pressure is normal, all of these goals will help you keep it that way. They are also recommended if your blood pressure is already high. Medicine is often part of the

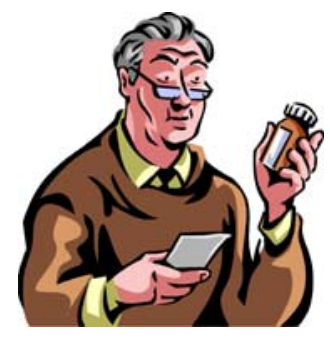
treatment for high blood pressure. It is better to keep your blood pressure from getting high in the first place.

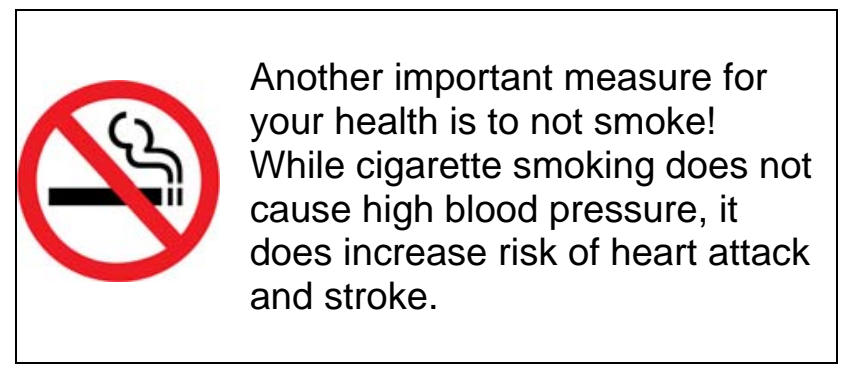

\section{Reaching your lifestyle goals}

You may wonder how to reach the goals outlined on this page. Help is available!

For more information on reducing your risk for high blood pressure, see the University of Florida Extension fact sheet, Living Well to Keep Your Pressure Down. It can be found at http://edis.ifas.ufl.edu/FY305. This fact sheet will give you tips for reaching all of the goals that are recommended to reduce your risk of high blood pressure.

\section{For more information}

\section{Cooperative Extension Service}

Your local county Extension agent may offer programs on blood pressure control, weight management, and other healthy living topics. In Florida, find your Extension office in the blue pages of your telephone book or online at: http://solutionsforyourlife.ufl.edu/map/.

\section{Hospitals}

Local hospitals may have lectures on topics related to cardiovascular health.

\section{Reliable Web sites:}

www.nhlbi.nih.gov/hbp/consumer

www.niddk.nih.gov/

www.americanheart.org/

www.strokeassociation.org/

www.stroke.org 